\title{
Petrology and geochemistry of annually laminated stalagmites from an Alpine cave (Obir, Austria): seasonal cave physiology
}

\section{IAN J. FAIRCHILD ${ }^{1}$ CHRISTOPH SPÖTL ${ }^{2}$, SILVIA FRISIA ${ }^{3}$, ANDREA BORSATO ${ }^{4}$, JEAN SUSINI $^{5}$, PETER M. WYNN ${ }^{6}$, JEAN CAUZID ${ }^{5,7}$ AND EIMF $^{8}$}

${ }^{1}$ School of Geography, Earth and Environmental Sciences, University of Birmingham, Edgbaston, Birmingham B15 2TT, UK (corresponding author, e-mail: i.j.fairchild@bham.ac.uk)

${ }^{2}$ Institut für Geologie und Paläontologie, Leopold-Franzens-Universität Innsbruck, Innrain 52, 6020 Innsbruck, Austria

${ }^{3}$ School of Environmental and Life Sciences, University of Newcastle, Callaghan, New South Wales, Australia

${ }^{4}$ Museo Tridentino di Scienze Naturali, Via Calepina 14, Trento 38100, Italy

${ }^{5}$ European Synchrotron Radiation Facility, F-38043 Grenoble Cedex, France

${ }^{6}$ Department of Geography, University of Lancaster, Lancaster, LA1 4YQ, UK

${ }^{7}$ G2R, Université Henri Poincaré, 54506 Vandœuvre-lès-Nancy, France

${ }^{8}$ Edinburgh Ion Microprobe Facility, Institute of Earth Science, School of Geosciences, University of Edinburgh EH9 3JW, UK

Abbreviated title: Annually laminated stalagmites, Austria

Abstract: Calcite stalagmites from Obir, an Alpine (1100 m altitude), perennially wet cave, were studied using optical and electron backscatter diffraction petrology, bulk ICP-MS analysis, and microanalysis by ion microprobe and micro-X-ray fluorescence using synchrotron radiation. Drip water penetrates $70 \mathrm{~m}$ through Triassic limestones (with some $\mathrm{Pb}-\mathrm{Zn}$ mineralization) to the chamber Säulenhalle where the stalagmites were collected and with which we compared drip water compositions. However, the cave is also characterized by strong seasonal ventilation, leading to low $\mathrm{PCO}_{2}$ in winter. All samples display autumnal event lamination defined by a narrow, optically visible zone with trace element enrichments, within which synchrotron studies have resolved micron-scale enrichments of $\mathrm{Pb}$ and $\mathrm{Zn}$. Crystallite-scale $(10 \mu \mathrm{m})$ lateral trace element variations reflect alternate smooth faces and rough crystal edges, induced by high Zn content. Seasonal falls in sulphate S and increase in $\delta^{13} \mathrm{C}$ can be associated with the winter ventilation. The elemental covariations support the transport of $\mathrm{Pb}, \mathrm{Zn}, \mathrm{P}, \mathrm{F}, \mathrm{Br}$ and I by organic colloids, but final depositions from aerosols rather than dripwater should be considered. The chemical variations are powerful expressions of seasonal cave physiology, but the study points to important gaps in our understanding of colloidal element transport in ventilated caves.

(end of abstract)

The current surge of interest in speleothems as recorders of environmental change (McDermott 2004; Fairchild et al. 2006a) has mostly focused on multi-millennial stable isotope time series with typically scant description of speleothem petrology. Nevertheless, it is known that certain disequilibrium speleothem fabrics are associated with non-equilibrium geochemistry (Frisia et al. 2000) and more generally that there are wide variations in the trace element composition of speleothems (Roberts et al. 1998, Borsato et al. 2007). In this article, we focus on the distinctive petrography and geochemistry of stalagmites from Obir cave in Austria as an exemplar both of the wealth of information preserved in speleothems and also the issues arising in chemical palaeoenvironmental proxies. The cave system has a strongly developed circulation system, which together with its hydrology, can be referred to as its physiology. We examine how this physiology impacts on the formation of stalagmites.

Spötl et al. (2005) described the distinctive pattern of seasonal variation of air circulation at Obir based on three years monitoring. The result was the formulation of a new model for $\delta^{13} \mathrm{C}$ 
variations in which: a) enhanced winter circulation leads to low $\mathrm{PCO}_{2}$, b) dripwaters develop high $\delta^{13} \mathrm{C}$ values by degassing isotopically light $\mathrm{CO}_{2}$ and c) supersaturations for calcite are increased. The expectation would be that, during the winter, stalagmites should grow faster and display high $\delta^{13} \mathrm{C}$ values.

The first stalagmite publication on Obir is by Smith et al. (2009), who use ${ }^{14} \mathrm{C}$ evidence to demonstrate that laminae in stalagmite Obi84 from the chamber Säulenhalle were annual, and that the laminae in this and two other similar stalagmites (Obi12 and Obi55) coincided with depletions in $\mathrm{Sr}$ and enrichments in several other trace elements. These patterns were used to test a new statistical model to determine speleothem growth rate from high-resolution chemical analyses. In this paper we show that annual chemical signals of ventilation $\left(\delta^{13} \mathrm{C}\right.$ and $\left.\mathrm{S}\right)$ can be identified, but question the assumption of our previous study (Smith et al., 2009) that annual enrichments in trace elements such as $\mathrm{Pb}, \mathrm{Zn}$ and $\mathrm{P}$, can be attributed to drip water transport, as in the model set up at Grotta di Ernesto, NE Italy (Borsato et al. 2007). Although the Ernesto site has similarities in terms of altitude (1100 m), forested setting, presence of laminated stalagmites, and preservation of S pollution history (Frisia et al. 2000, 2003, 2005; Fairchild et al. 2001; Huang et al. 2001; Borsato et al. 2007; Wynn et al. submitted), the deeper Obir site displays several differences. Specifically Obir displays neither the significant increases in dripwater flows during the autumn and nor the correlation between growth rate and temperature that are characteristic of Ernesto. The relationship between chemistry of Obir stalagmites and instrumental climate records generally are not simple and hence we do not discuss climatic inferences in detail in this paper. The focus instead is on demonstrating the remarkable annuallyvarying physicochemical properties of the stalagmites as shown by a series of state-of-the-art analytical techniques.

\section{Methods}

Thin sections for petrography and ion microprobe analysis for stalagmite samples Obi12, 55 and 84 were polished and c. $150 \mu \mathrm{m}$ thick. Lamina thickness measurement was carried out on a polarizing microscope using a graticule in which the smallest division was $5 \mu \mathrm{m}$, making frequent use of photomosaics, and varying the optical conditions to optimize lamina visibility. In Obi84, the thickness of the last 140 laminae was measured in at least three traverses and the mean value determined.

A representative piece of the top cm of sample Obi84 sample was ground into a powder in a pestle and mortar and analysed using a Siemens D5000 diffractometer in transmission geometry. Data were collected in $0.02^{\circ}$ steps with a counting time of $11 \mathrm{~s} / \mathrm{step}$ over the range $2 \theta 10^{\circ}$ to $80^{\circ}$. A Rietveld refinement was carried out in GSAS (Larson and Von Dreele 2000).

The ESBD analyses were acquired using the HKL Channel5 ESBD analysis system on the Philips XL30CP SEM in the School of GeoSciences, University of Edinburgh. The SEM was operated at an accelerating voltage of $20 \mathrm{kV}$ and a $\sim 2 \mathrm{nA}$ beam at a working distance of $20 \mathrm{~mm}$ and a tilt angle of $\sim 70^{\circ}$. The sample was given a final colloidal silica polish to remove surface crystal damage after mechanical polishing and the sample was used uncoated with the SEM operating at a controlled pressure of $0.1 \mathrm{mBar}$ to minimise any charging effects. For each point the diffraction pattern was collected and solved by the software for the calcite crystal structure to within $<1^{\circ}$. Maps for the orientation of the crystal structure of the sample were generated from point analyses collected every $1 \mu \mathrm{m}$ over a $2 \times 2$ grid of maps each approximately $500 \mu \mathrm{m}$ wide and which were subsequently tiled together to form the final map. The whole map was then processed to highlight any variation in orientation of the crystal structure within the sample.

Samples for stable oxygen and carbon isotope analysis were micromilled at $100 \mu \mathrm{m}$ intervals for all three stalagmites (using methods as in Spötl \& Mattey 2006). Measurements were performed using an on-line, automated carbonate preparation system linked to a triple collector gas source isotope ratio mass spectrometer at Innsbruck University. Values are reported relative to VPDB standard. Longterm precision of the $\delta^{13} \mathrm{C}$ and $\delta^{18} \mathrm{O}$ values, estimated as the $1 \sigma$-standard deviation, is 0.06 and $0.08 \%$, respectively (Spötl \& Vennemann, 2003). Methods for water analyses are given in Spötl et al. (2005). 
ICP-MS analysis was conducted at the NERC ICP-MS facility at Kingston University UK, on drilled sub-samples from stalagmites and as a re-analysis, following acidification, of some drip waters up to three years after collection. An Agilent single-collector instrument was used, supplemented by a high mass-resolution Axiom instrument for $\mathrm{S}$ and $\mathrm{P}$ analysis of dissolved speleothem powders, as reported in Frisia et al. (2005). Both solutions from speleothem powders (50 mg in $100 \mathrm{mls}$ solution) and acidified waters were analyzed in a matrix of $2 \%$ Aristar-grade $\mathrm{HNO}_{3}$. Standardization procedures are as reported in Borsato et al. (2007) and all reported results are well above calculated detection limits with analytical precision of $\leq 5 \%$.

Ion microprobe analysis at the Edinburgh Ion Microprobe Facility (EIMF) was carried out under a variety of experimental conditions using polished gold-coated samples. One sub-set of analytical work was summarized by Smith et al. (2009), with more examples being given here. This used similar methods to those of Fairchild et al. (2001) and Borsato et al. (2007), using a Cameca ims-4f instrument, with a primary $20 \mathrm{nA}$ beam of diameter c. $30 \mu \mathrm{m}$. Each of the three stalagmite samples was bombarded with a primary $\mathrm{O}^{-}$beam leading to sputtering of secondary ions of ${ }^{1} \mathrm{H}^{+},{ }^{23} \mathrm{Na}^{+},{ }^{26} \mathrm{Mg}^{+},{ }^{31} \mathrm{P}^{+},{ }^{44} \mathrm{Ca}^{+},{ }^{88} \mathrm{Sr}^{+}$ and ${ }^{138} \mathrm{Ba}^{+}$which were measured. The step scan mode was used to analyse the sample at approximate 5 $\mu \mathrm{m}$ intervals, with ions being drawn from an area with an approximate diameter of $8 \mu \mathrm{m}$. Measurements were taken along linear traverses at 5 or $10 \mu \mathrm{m}$ intervals. Precision of results for most elements is typically $1-5 \%$ (but worse for $\mathrm{H}$ and $\mathrm{Na}$ whose analyses are regarded as semi-quantitative because of variable surface effects); $\mathrm{Mg}, \mathrm{Sr}$ and $\mathrm{Ba}$ were referred to a carbonate standard (Oka) and other elements to an apatite standard (Durango) with agreement within $10 \%$ of mean bulk analyses as determined by Borsato et al. (2007).

Sample Obi84 was also analysed on the Cameca ims-1270 instrument at the EIMF under three different experimental conditions using a primary $\mathrm{Cs}^{+}$beam to generate negative secondary ions. Precise analysis of ${ }^{13} \mathrm{C} /{ }^{12} \mathrm{C}$ ratios was carried out in two sessions in February and May 2005. The primary beam current was $30 \mathrm{nA}$ (February) or 40-45 nA (May), and a 50-60 $\mu \mathrm{m}$ image field, to yield an elliptical analytical spot. The area of gold removed is typically 35 by $30 \mu \mathrm{m}$, but SEM analysis of February pits showed a pit 13-20 by $20 \mu \mathrm{m}$ with a narrow core about 6 by $6 \mu \mathrm{m}$. Secondary carbon ions of masses 13 and 12 were simultaneously collected using two Faraday cups. High transmission and a high beam current was necessary to obtain sufficient counts $\left(\geq 1.5^{*} 10^{6} \mathrm{cps}\right.$ on $\left.{ }^{13} \mathrm{C}\right)$. Charge neutralization was achieved using a normal incidence electron gun. Each analysis consisted of 20 blocks of 5 seconds measurement time following a period of pre-sputtering. Analysis of a group of 2050 sample points alternated with blocks of 10 analyses of standard UWC (University of Wisconsin calcite, which has a composition of $-2.14 \%$ oovsmow determined by multiple bulk analyses by J.W. Valley). Analytical points were spaced at $30-60 \mu \mathrm{m}$ to avoid surface charging effects and their X-Y coordinates were recorded automatically. The 1-sigma precision on 10 successive spots on the UWC standard was normally $<0.6$ per mil. For $\mathrm{S}$ and $\mathrm{P}$ analysis in May 2005, a primary beam current of 4.5 nA were used with Köhler illumination to generate an analytical spot around 20-25 $\mu \mathrm{m}$ in size. The instrument was used in line scan mode ( 10 or $15 \mu \mathrm{m}$ step) with a pre-sputter reduced to 10 seconds. Ratios of the secondary ions of ${ }^{31} \mathrm{P}$ and ${ }^{32} \mathrm{~S}$ (at a mass resolution of 2500 to distinguish from $\mathrm{O}_{2}$ ) to ${ }^{13} \mathrm{C}$ were counted using an electron multiplier. Results have a precision of better than $2 \%$ from counting statistics, but were not standardized. Analysis of ${ }^{31} \mathrm{P}^{-}$and halogen elements $\left({ }^{19} \mathrm{~F}^{-},{ }^{35} \mathrm{Cl}^{-},{ }^{37} \mathrm{Cl}^{-},{ }^{79} \mathrm{Br}^{-}\right.$, ${ }^{81} \mathrm{Br}^{-}$and ${ }^{127} \mathrm{I}^{-}$) was undertaken in November 2008 with a $1 \mathrm{nA}$ primary beam focused to a diameter of c. $10 \mu \mathrm{m}$. Analysis was in line scan mode, stepping at $5 \mu \mathrm{m}$ between analyses, which also had the effect of cleaning the sample by pre-ablation. Analytical precision is limited by counting statistics and is $<1 \%$ for $\mathrm{Cl}, 2-3 \%$ for $\mathrm{P}$ and $3-4 \%$ for $\mathrm{Br}$ and $\mathrm{I}$. Halogen concentrations were standardized by direct comparison with a lead-silicate glass K1053. The absolute ion yields for the halogens were confirmed as being very high, varying from 5.0 (for $\mathrm{F}^{-}$) to 0.86 (for $\mathrm{I}^{-}$) times that of $\mathrm{O}^{-}$. The effects of sample matrix on ion yields on the silicate glass compared with carbonate are currently unknown.

Sample Obi84 was analyzed at the European Synchrotron Research Facility using soft X-rays at beamline ID21 in May 2005 and using hard X-rays at beamline ID22 in December 2006. For beamline ID21, experimental details are similar to those given in detail in Frisia et al. (2005). Samples were prepared as thin $(<1 \mathrm{~mm}$ thick) slabs up to around 22 by $19 \mathrm{~mm}$, with polished upper surfaces and were 
mounted with double-sided tape to a circular $3 \mathrm{~cm}$-diameter holder. The samples were excited with monochromatic synchrotron radiation of $2.9 \mathrm{keV}$ in order to stimulate $\mathrm{K} \alpha$ radiation from light elements (up to $\mathrm{Cl}$ ). Ca was not analysed, but the consistent beam conditions permit the assumption that excitation conditions were consistent; minor reductions in beam intensity of up to $10 \%$ were corrected for. Specific energy levels within the resultant X-ray fluorescence spectrum characteristic of particular elements were then studied in scans and maps. The X-rays were predominantly generated at depths of just a few microns in the sample and maximum penetration of the exciting radiation was 20-30 $\mu \mathrm{m}$. The beam was focused to either $5 \mu \mathrm{m}$ (scans and maps) or, for a high-resolution map using $1 \mu \mathrm{m}$ pixels the beam was focused to 0.6 by $0.3 \mu \mathrm{m}$, but resolution is limited by the slightly larger excitation volume.

At beamline ID22, the conditions are mostly similar to those described in detail by Borsato et al. (2007), but some differences are noted here. The sample was prepared as a doubly-polished wafer of thickness around $150 \mu \mathrm{m}$, mounted over a hole in the sample holder. Excitation energy used was 23 $\mathrm{keV}$, enabling in principle the detection of the K-lines of all the elements up to atomic number 47 and of the L-lines of other elements. The spectrum was deconvoluted by using PyMCA software (Solé et al. 2007) and detection limits were found to be sub-ppm level for $\mathrm{Ca}, \mathrm{Sr}, \mathrm{Zn}$ and $\mathrm{Pb}$, but analysis of other elements was limited by elemental interferences. Elemental mapping was carried out with a $2 \mu \mathrm{m}$ resolution over a length of $1.1 \mathrm{~mm}$ and $5 \mu \mathrm{m}$ resolution over a width of $0.1 \mathrm{~mm}$. The fluorescence signal was integrated for 2 seconds in each pixel. The information depth is defined at the depth to which $63 \%$ of the characteristic X-ray line intensity of an element is being collected and depends on the $\mathrm{X}$-ray energy. It varies from around $17 \mu \mathrm{m}$ for $\mathrm{Ca}$ to $110 \mu \mathrm{m}$ for $\mathrm{Sr}$. The generation of X-rays over a range of depths for heavier elements results in a more complex pattern than in a strictly twodimensional image, but unlike tomographic images it is not possible to distinguish which are shallower and which are deeper sites of X-ray generation.

\section{Study site and dripwater characteristics}

The local context of Obir is only briefly described here, being summarized from Spötl et al. (2005). The cave is on the eastern flank of the Hochobir massif $\left(46.51^{\circ} \mathrm{N}, 14.54^{\circ} \mathrm{E}\right), 22 \mathrm{~km} \mathrm{SE}$ of Klagenfurt, Austria. One distinct group of cave passages within the cave system is accessible only through an adit from an abandoned $\mathrm{Pb}-\mathrm{Zn}$ mine at an altitude of $1090 \mathrm{~m}$. Here several chambers around $200 \mathrm{~m}$ into the hillside have been monitored, displaying a remarkably congruent pattern of variation in $\mathrm{PCO}_{2}$ through the year. Of these, Säulenhalle lies at a depth of ca. $70 \mathrm{~m}$ from the surface and is accessible via a narrow horizontal passage opening to a chamber several metres in size in each dimension. The overlying vegetation is a spruce-dominated forest underlain by a brown forest soil. Annual precipitation lies within the range $1100-1600 \mathrm{~mm}$, mostly in the second half of the year and the water-excess peaks in October and November. The temperature is below freezing normally between November and March and the ground is snow-covered for most of this period. The air temperature in Säulenhalle, which should be close to the annual mean, is $5.8 \pm 0.1^{\circ} \mathrm{C}$ throughout the year and dripwaters in the same chamber are $5.8 \pm 0.2{ }^{\circ} \mathrm{C}$.

Spötl et al. (2005) presented several years of hydrochemical data from three representative drips in the cave system which varied from near-invariant in drip rate to displaying modest seasonal changes through to more extreme and inter-annual variability. Despite differences in hydrological behaviour they showed a consistent pattern of seasonal changes in the carbonate system, but no seasonal variations in other chemical parameters. In the winter: 1) $\mathrm{pH}$ rises, in equilibrium with changing $\mathrm{PCO}_{2}$ of cave air and calcite saturation rises similarly, 2) $\delta^{13} \mathrm{C}$ of dissolved inorganic carbon rises from a base of -11.2 to $-11.9 \%$ o by 2 to $7 \%$ os isotopically light $\mathrm{CO}_{2}$ is degassed, 3) in some drips, there is a modest decrease in $\mathrm{Ca}$ and alkalinity (most precisely monitored by changes in the electroconductivity of the solution) indicative of some $\mathrm{CaCO}_{3}$ precipitation; winter precipitation is also seen on the surface of a pool (Silbersee) in Säulenhalle.

The three studied stalagmites from Säulenhalle (Obi12, Obi55 and Obi84) are all approximately cylindrical structures $3-4 \mathrm{~cm}$ in diameter fed by stalactites a few $\mathrm{cm}$ to $\mathrm{dm}$ above. The elemental 
composition of four drip water sites, including the three feeding the three stalagmites, is summarized in

Table 1. The drips feeding the studied stalagmites are very similar in: 1) major and minor element compositions, 2) the consistent $\mathrm{Ca}$ concentrations of $51-53 \pm 5 \mathrm{mg} \cdot 1^{-1}$ and 3) calcite saturation indices (around $0.44-0.58 \pm 0.1$ ) controlled by seasonally changing ventilation.

Generally, no relationship between instantaneous measurements of drip rate and EC (electrical conductivity, a proxy for total ion content) was found. SH2, which feeds a stalagmite that has not been collected, was an exception in that at the slowest drip rates of down to $0.36 \mathrm{mlhr}^{-1}$, EC was low and correlated with low $\mathrm{Ca}$ and hence high $\mathrm{Mg} / \mathrm{Ca} ; \delta^{13} \mathrm{C}$ was also high. This is indicative of prior calcite precipitation stimulated by degassing (Fairchild et al. 2000; Fairchild and McMillan 2007).

Data on drip rates (from a tipping bucket drip logger), water and air temperature is illustrated in Figure 1. None display a simple seasonal pattern of variation; in particular there is no sign of an increased drip rate during peak infiltration during the autumn season. Drip SH4, feeding Obi84, was not continuously logged, but over a period of two years maintained a relatively high drip rate that would have ensured steady growth. Drips SH1 to SH3 all displayed inter-annual growth variations; the most pronounced relative change was SH1 (Obi12) which displayed a pronounced decline from 2000 to 2003 (confirming instantaneous drip rates presented in Spötl et al. 2005) when monthly volume collections indicated drip rates as low as $0.36 \mathrm{mlhr}^{-1}$.

Figure 1 illustrates a more regular pattern of variation of temperature of drip water (using SH3 Obi55 as a typical example), displaying an upward deviation compared with summer values of around $0.1^{\circ} \mathrm{C}$ in the first part of winter followed by a larger drop and gradual recovery later in the winter. Air temperature in Säulenhalle displays a similar pattern, although the upward displacement is more typically $0.2-0.3^{\circ} \mathrm{C}$. Since the air circulation is so extensive (Spötl et al. 2005), we argue that the deviations in the water temperature are controlled by the seasonal air circulation. Some spot measurements of air velocity have been made at the narrow squeeze at the entrance to Säulenhalle as well at the next one which leads to subsequent chambers: maximum air velocities of ca. $0.5 \mathrm{msec}^{-1}$ are reached during winter.

\section{Petrology}

\section{Crystal fabrics}

The successive growth layers of the stalagmite are made visible by the presence of internal laminae which are parallel to the external surface of each stalagmite (Fig. 2a). A slight depression toward the centre of the stalagmites likely reflects the impact point of the feeding droplets. Fig. $2 \mathrm{~b}$ highlights the characteristics of the columnar fabrics which compose Obir stalagmites. These, as for other speleothems, are aggregates of crystals that precipitated synchronously from the same medium to form single growth layers. The "synchronous" crystals precipitated in each growth layer (where the unit of "synchronous" time could be a year or a season) are commonly referred to as "crystallites", following Kendall \& Broughton (1978), to distinguish them from the composite columnar individuals which are typically recognized by their systematic extinction.

The fabrics in the best-studied example (Obi 84) are transitional from columnar to microcrystalline types as defined by Frisia et al. (2000). Columnar fabric is commonly characterized by the parallel arrangement of prismatic crystals (Onac, 1997), where the equal orientation of the crystals is related to a common direction of most rapid growth. In microcrystalline fabric, some individuals within the aggregate are not parallel or sub-parallel to the adjacent individuals and their direction of most rapid growth is not the same as that of the majority of the individuals within the aggregate. In the centre of Obi84 (Fig. 2b), extinction sweeps regularly as a wave through the crystals (with a total variation of up to $20^{\circ}$ ), similar to the variation in orientation of growth layers) but crystal boundaries are typical of columnar calcite. However, the extinction sweeps counter to the crystal elongation (see crystal S in Fig. 2b) in the manner of radiaxial calcite, which has recently been recognized in a Mg-bearing calcitic speleothem sample by Neuser \& Richter (2007). In speleothems, radiaxial fibrous calcite aggregates have been interpreted as being the product of crystal splitting, i.e. where individual crystals split through various mechanisms, among which because ions with a 
"poisoning" effect on growth sites are present in the parent solution or because ions with a larger ionic radius substitute for ions in the mineral structure. The final form of crystal splitting is a spherulite (Onac, 1997). Further from the growth axis, the composite crystal aggregates are closer to the microcrystalline fabrics described by Frisia et al. (2000), the latter representing a type of columnar fabric forming when growth inhibitors or drip rate variability characterize the system (Frisia et al., 2000). High-resolution analysis of this microcrystalline calcite has been achieved using electron backscatter diffraction in an area about $8 \mathrm{~mm}$ below the top of sample Obi84 (Fig. 2b) and is illustrated in Fig. 2c. Fig. 2c shows a mosaic of small crystallites, with grain boundaries which range from well defined to more "diffuse", typically around 20 by $10 \mu \mathrm{m}$. There is a clear preferred orientation of the individuals roughly from the left bottom corner to the right upper corner of Fig 2c. This direction coincides with the overall orientation of the aggregate crystal which has been analysed (see the area of the map in Fig. 2b). The relative crystallographic orientation of each small crystal (or crystallite) within the aggregate is indicated by the false colours of Fig. $2 \mathrm{c}$ and correspond to the orientations shown in the stereographic projections of Fig. $2 \mathrm{~d}$. The crystallites show a range in orientation by up to around $15^{\circ}$ within each crystal, but adjacent crystallites are often mismatched by only $1-2^{\circ}$. The pole to $\{0001\}$ in Figure 1d (left), which also corresponds to the $<0001>$ zone axis cluster near the centre of the projection, indicating that the $\mathrm{z}$ crystallographic axes are near-vertical with respect to the surface of the sample section shown in Fig. 1c and sub-parallel to the growth surface at the top of the speleothem.

SEM analysis at the sample top (Fig. 3b) reveals that the morphology of the calcite crystals is characterized by sub-micrometre-scale macrosteps. Some flat faces also developed which are apparently all parallel to each other. This contrasts with the more usual situation in stalagmites (Frisia et al. 2000), where SEM observations reveal that speleothem surfaces are characterized by the emergence of rhombohedral tips. The scaling indicates that each flat face may correspond to a single crystallite on the EBSD image. If the orientation analysed by EBSD on a portion of the stalagmite holds true for the rest of the specimen, as is supported by the extinction patterns as seen by optical microscopy, possible candidates for the flat faces which developed at the top of the Obir stalagmites are those that lie in the equatorial plane of the stereographic projection and pointing towards the top of the sample as in Fig. 1d. Plots for various prismatic, rhombohedral and scalenohedral forms are shown and the most likely example is a face in the $\{10-11\}$ rhombohedral form (Fig. 1d) and not the usual (cleavage-parallel) rhombohedral faces $\{10-14\}$. Later in the paper, we interpret the presence of macrosteps and the overall morphology of the calcite crystals of Obir stalagmites as being controlled by the presence of impurities in the parent solution.

\section{Visible annual lamination}

The top few centimetres of stalagmite Obi84 display a consistent structure in which narrow visible laminae, shown to be annual by Smith et al. (2009), are spaced at ca. 100-200 $\mu$ m intervals. Similar laminae are also developed in the other two samples, but their development is less consistent. The stalactite feeding Obi55 was collected and also displays such laminae, but very close-spaced. Where most distinctly developed in stalagmites, the laminae are a few microns wide and may be nearly flat in geometry, but more commonly display a zig-zag shape. Usually the zig-zags have a relief of a few micrometres, but this can exceptionally be up to $200 \mu \mathrm{m}$ where it is followed by the development of a large air inclusion (Fig. 3a). Some years show a more complex structure in which two or three such laminae are found close together, although the optical imaging of these is complicated by internal reflections (Fig. 4a). The zig-zag shapes have dimensions consistent with those of the crystallites in Figs. 2c and Fig. 3b. Laterally, some laminae may become diffuse and apparently are composed of a zone of fluid inclusions, locally inclusions forming vertical trains at crystallite margins. These areas are interpreted as representing places where crystallites coalesced just below the growth surface (as in Kendall \& Broughton 1978).

In Obi84, which was collected in December 2002, the latest visible lamina lies very close to the top surface (Fig. 3a), implying that it formed in the autumn. In the review of Fairchild et al. (2007), we presented a similar figure to Fig. $3 \mathrm{a}$ and identified these features as infiltration laminae, implying a 
310 formation by infiltration of water excess (Fairchild et al. 2006a), but we now regard this interpretation as suspect, and here use the term event laminae instead.

Re-nucleation horizons are present in each of the three samples and are sufficiently prominent as to suggest they each represent a hiatus in growth. However, it is notable that the hiatuses do not contain enrichments in insoluble residues or signs of corrosion, and so are distinct from those that represent significant time gaps in speleothems (Tan et al. 2006). Indeed, close study of the prominent event shown in Fig. 4c reveals that locally growth continues through the event and that it is no more than two or three years in duration (Fig. 4d). The prominent hiatus in Obi84 occurs at the level of the 1834-1835 A.D. laminae around $23 \mathrm{~mm}$ below the top, whereas in Obi55 there is one just $9 \mathrm{~mm}$ from the top and in Obi12 at $12 \mathrm{~mm}$ from the top. However, the statistical analyses of Smith et al. (2009) show that the growth rate of each stalagmite is similar.

An example of an incipient hiatus, representing probably of the order of a month's gap in growth, is shown between the 1999 and 2000 annual layers in Fig. 3a. Essentially it represents a renucleation horizon where some new crystallites of diverse optical orientation are found and which can persist upwards (e.g. the upwards-expanding crystallite under the word "top" in Fig. 3a). Such an intrayear hiatus can be seen to pass laterally into a more profound pause in growth in Fig. $4 \mathrm{~b}$ and this is typically of the lamina geometry as they are traced into the flanks of the stalagmites.

In summary, it is notable that hiatuses are developed at different times in the three specimens and that they do not represent significant time gaps. The presence of inter-annual slowdowns in drip rate mentioned earlier in the paper (and found elsewhere, e.g. by Baldini et al. 2006) provides a possible mechanism for hiatus development, growth being limited by lack of ion supply through dripwater. Where the monitored drip rates go well below $0.36 \mathrm{mlhr}^{-1} 1 \mu \mathrm{sec}^{-1}$, significantly slower growth would be expected from the quantitative model of Dreybrodt (1988) and Baker et al. (1998). However, since the different drips in Säulenhalle do not vary in discharge synchronously, this phenomenon is not of climatic significance.

The lamina chronology for Obi84 for the past 140 years is shown in Fig 5b. The mean annual growth thickness is $141 \pm 25 \mu \mathrm{m}$ and the robustness of the series is shown by the low relative standard deviation of measurement of any individual year, which is $19 \%$. Note that there is an overall reduction in annual growth thickness with time. This contrasts with the record in Grotta di Ernesto stalagmites where there is a strong increase, correlated with Northern Hemisphere temperature trends (Frisia et al. 2003; Smith et al. 2006).

\section{Trends in chemical composition and comparison with dripwaters}

\section{Trace elements}

Figure 5 summarizes the variations in chemistry found in stalagmites Obi84 (Fig. 5a, c) and Obi12 (Fig. 5d) over the past 200 years. Trace elements, including some additional elements not showing temporal variation, are also summarized in Table 2 . The most unusual feature about both samples is their extremely high content of $\mathrm{Zn}$ (typically around $5000 \mathrm{ppm}$ ) and $\mathrm{Pb}$ (400-1400 ppm). These contents tend to reduce over time, albeit somewhat irregularly from the early $19^{\text {th }}$ century to the late $20^{\text {th }}$ century. Cu shows a similar trend in Obi84, but concentrations are low. Other trace elements $(\mathrm{Mg}$, $\mathrm{P}, \mathrm{Mn}, \mathrm{Y}, \mathrm{Sr}$ and $\mathrm{Ba}$ ) show steady compositions, but $\mathrm{S}$ (present in the calcite in the form of sulphate) increases strongly with time. This parallels the impact of late $20^{\text {th }}$ century pollution recorded in speleothem ER78 from Ernesto cave (Frisia et al. 2005). In work to be presented elsewhere, we confirm this using the first in-situ micro-measurements of $\delta^{34} \mathrm{~S}$ in carbonate-associated sulphate.

The trace element content explains X-ray diffraction data which demonstrate that there is a small reduction in (hexagonal) unit cell size $(\mathrm{a}=4.985 \AA, \mathrm{c}=17.042 \AA)$ compared with pure calcite (a $=4.9896 \AA$, c: $17.06 \AA$, Reeder 1983). The mean composition of the top cm of the sample in molar terms is $\mathrm{Ca}_{0.989} \mathrm{Zn}_{0.0070} \mathrm{Mg}_{0.0042} \mathrm{~Pb}_{0.0003} \mathrm{CO}_{3}$. For ions that form isomorphous carbonates with calcite, there is a linear change in unit cell size with substitution of trace species and both $\mathrm{Mg}$ and $\mathrm{Zn}$ have the effect of decreasing cell size. From data in Reeder (1983) and Mackenzie (1983), and assuming an additive effect of the two ions, the observed $\mathrm{Mg}$ and $\mathrm{Zn}$ concentrations predict parameters of $\mathrm{a}=4.986$ 
$\AA$ and $17.038 \AA$, very close to the observed values. Therefore, it is interpreted that these ions are dominantly substituted for $\mathrm{Ca}$.

For $\mathrm{Mg}$ and $\mathrm{Sr}$, it is appropriate to calculate a distribution coefficient to express the fractionation in the ratio of the ion to calcium where:

(1) $(\mathrm{Tr} / \mathrm{Ca})_{\mathrm{CaCO} 3}=\mathrm{K}_{\mathrm{Tr}} *(\mathrm{Tr} / \mathrm{Ca})_{\text {solution }}$

where $\operatorname{Tr}$ is the trace ion and $\mathrm{K}_{\mathrm{Tr}}$ is the distribution coefficient, which may vary to a greater or lesser extent with temperature, precipitation rate, crystal morphology, or other aspects of solution (Fairchild and Treble 2009). The resulting values in Table 3 are reasonably consistent with those observed by slow-growth, low ionic-strength experiments and in Ernesto cave speleothems (Huang and Fairchild 2001), but kinetic and competition factors are known to be important for Sr (Borsato et al. 2007).

The behaviour of sulphate is being studied in much more detail and will be presented elsewhere, but it should be noted that the concentrations in drip water and in the speleothems are similar to the Ernesto stalagmite ER78 (Frisia et al. 2005). In both cases sulphate partitions into calcite to a lesser extent than would be expected from the experiments of Busenberg and Plummer (1985), which were conducted at relatively fast growth rates using high ionic strength solutions.

For other solutes, the partition coefficient concept is not so applicable and it is also more difficult to obtain water analyses for many species. Borsato et al. (2007) found that at Ernesto metals such as $\mathrm{Pb}$ and $\mathrm{Zn}$, as well as $\mathrm{P}$, strongly adsorbed to collection vessels because of being transported in the form of unstable colloids. Obir water samples are normally collected monthly, or less frequently from cumulative collection vessels, although some direct samples were taken from drip SH4 from 2002 to early 2004. On realizing the importance of colloidally transported elements, in November 2005, we re-analyzed remaining previously collected samples from drips SH3 and SH4, acidifying those samplies where that had not previously been done (to release adsorbed elements) and carried out ICPMS analysis on additional elements. Data from SH3 (feeding Obi55) and SH4 (feeding Obi84) are presented in Table 4 and results are generally consistent between the two. The Fe, Al and Si probably represent colloidal particles, but organic colloids could be even more important (Fairchild and Treble, 2009). $\mathrm{Pb}, \mathrm{Zn}$ and $\mathrm{Y}$ (all elements inferred to be colloidal transported at Ernesto Cave) have, as expected, high variations in abundance in contrast with $\mathrm{Sr}$ and Ba which are expected to be very largely present as free ions. There were no obvious seasonal variations in abundance.

Empirical distribution coefficients, as in equation (1), between the dripwater data of Tables 1 and 4 and the composition of the top $10 \mathrm{~mm}$ of the stalagmite are shown in Table 5. The calculated values for $\mathrm{Zn}$ and $\mathrm{Pb}(>>1)$ are consistent with experimental and theoretical data summarized by Rimstidt et al. (1998) and Curti (1999) and with the evidence of strong sorption of these elements to calcite surfaces (Zahara et al., 1991; Godelitsas et al. 2003, Chada et al. 2005). The values of $<<1$ for $\mathrm{Cu}$ and $\mathrm{Y}$ are quite inconsistent with data in Rimstidt et al. (1998) and Curti (1999) where values $>>1$ can be predicted, using rare earth elements as a model for $Y$. This discrepancy can be accounted for if these elements are more tightly bound to colloids than are $\mathrm{Zn}$ and $\mathrm{Pb}$, such that $\mathrm{Y}$ and $\mathrm{Cu}$ are not so readily available for incorporation into calcite.

\section{Stable isotopes}

The mean stable isotope composition of the top $2 \mathrm{~mm}$ (approximately 20 years) of growth of sample Obi84 is $-6.27 \pm 0.36$ and $-7.83 \pm 0.23 \%$ for $\delta^{13} \mathrm{C}$ and $\delta^{18} \mathrm{O}$, respectively. In the case of $\delta^{13} \mathrm{C}$ there is a direct comparison with the aqueous $\delta^{13} \mathrm{C}$ composition since the fractionation between $\mathrm{CaCO}_{3}$ and dissolved inorganic carbon at the $\mathrm{pH}$ values of interest is very small (Mühlinghaus et al. 2007). The mean value for drip SH4 (which is very close to those from SH3) is $-10.25 \pm 0.74 \%$ oo $(\mathrm{n}=19)$ Table 1. However, the pattern of seasonal variation of aqueous $\delta^{13} \mathrm{C}$ (with a maximum of $-8.36 \%$ representing as one of only two points higher than $-9 \%$ o ) is less strongly developed than for the more slowly dripping points $\mathrm{SH} 1$ and $\mathrm{SH} 2$, which display increases of around 3 and $8 \%$ oo from the low summer levels of $-11 \%$ (Spötl et al. 2005). Hence the mean difference of $4 \%$ oo between SH4 drip water and the stalagmite is likely to reflect continued degassing perhaps with some kinetic effects during precipitation. 
The $\delta^{18} \mathrm{O}$ composition of dripwater feeding SH4 is $-10.23 \pm 0.10 \%(\mathrm{n}=18)$. Using the experimentally determined fractionation factors of Kim and O'Neil (1997), such water should precipitate calcite at equilibrium at a temperature of $5.5^{\circ} \mathrm{C}$ with a composition of $-8.4 \%$. The difference with the observed composition of $0.6 \%$ might indicate a small kinetic effect, but such a discrepancy is very commonly observed in natural speleothems (McDermott et al. 2005).

No detailed treatment of the variation in stable isotopes with depth is attempted here. However, we can note that over time the isotopes show rapid shifts from covariations to antipathetic variation and there are no strong correlations with mean temperature, winter temperature or rainfall in the instrumental period.

\section{Seasonal variations in chemical composition}

\section{Carbon isotopes}

The monitoring data show that enhanced ventilation during the winter season is a key process at Obir. The winter season is associated with low $\mathrm{PCO}_{2}$ which is found to control the $\mathrm{pH}$ of dripwater by enhancing the degassing towards equilibrium (Spötl et al. 2005). The high $\delta^{13} \mathrm{C}$ values found in dripwater should be expected to be seen in winter speleothem growth. In faster-growing stalagmites, it has recently proved possible to micromill sub-samples and demonstrate seasonal variations in $\delta^{13} \mathrm{C}$ (Frappier et al. 2002, Johnson et al. 2006, Mattey et al. 2008), but the Obir laminae are too thin for this to be done. Hence, we made the first attempt to determine such variations in terrestrial samples by ion microprobe.

The work was focused primarily around a group of relatively thick annual laminae which formed between 1958 and 1966. Interlaced forward-and-back trains of ablation pits were created during the analysis which was repeated in some parallel traverses (Fig. 6b). The work was technically extremely demanding because of the high beam current that was required leading to frequent electrical discharges that terminated the analysis. Enough data was collected however to demonstrate that considerable intra-annual variability is present with an amplitude of up to $6 \%$ ond always at least 2 $\%$, although the magnitude could not be reproduced between analytical tracks. The bulk of the heavier analyses were in the first half of the growth following the position of the visible infiltration lamina (Fig. 6b) which is consistent with the expectations from the cave monitoring.

\section{Sulphate}

Sulphate can be expected to vary in abundance with seasonal ventilation because of the influence of $\mathrm{pH}$ on its incorporation into calcite. Frisia et al. (2005) noted a significant annual variation in sulphate in stalagmite ER78 from Ernesto Cave which was attributed to $\mathrm{pH}$ changes, based on the model of Busenberg and Plummer (1985). These authors proposed that sulphate incorporation could be modelled by a distribution coefficient approach where the ratio of interest (cf. equation (1)) was $\mathrm{SO}_{4}{ }^{2-}$ $/ \mathrm{CO}_{3}{ }^{2-}$. Since aqueous sulphate does not vary through the year, and the abundance of $\mathrm{CO}_{3}{ }^{2-}$ is primarily controlled by $\mathrm{pH}$ in terms of its over-riding control on the ratio of $\mathrm{HCO}_{3}{ }^{-}$(the more abundant species) to $\mathrm{CO}_{3}{ }^{2-}$, a low value for sulphate in the speleothem each winter would be expected.

As was done by Frisia et al. (2005), synchrotron radiation was used to confirm that S in Obi84 was present as sulphate using the position of the dominant X-ray absorption peak. However, quantitative analysis of S content was impossible by this method because the K $\alpha$ emission line was swamped by $\mathrm{Pb}$. Instead, the ion microprobe was used to analyze $\mathrm{S}$, utilizing negative secondary ions, which permitted the simultaneous determination of P. A relatively large spot size of 20-25 $\mu \mathrm{m}$ was used, so laminae were crossed obliquely to compensate for this. No S standard was available at the time the analyses were done, so results are presented as ratios to ${ }^{13} \mathrm{C}$. Results for the 1958-1966 laminae illustrate that $\mathrm{P}$ peaks lie close to or precisely on the visible event lamina. In comparison with this, $\mathrm{S}$ also shows annual-scale variability, but it is offset from P. Figure 6a illustrates that in most cases the low values also occur predominantly from around the time of deposition of the visible lamina through to the first half of the next year's growth. A similar approach was taken to analyzing the last few years of growth at the top of the sample (Fig. 7). Here laminae were not visible in the precise area 
analyzed, but their thicknesses on a lateral part of the section are in agreement with the lamina positions that can be deduced from the $\mathrm{P}$ peaks (although it should be noted that the $1997 \mathrm{P}$ peak is very small and the $2000 \mathrm{P}$ peak is double). Again the low-S analyses are found to be overlapping with and following the $\mathrm{P}$ peaks, consistent with their formation during the winter period. An additional feature of Fig. 7 is that an overall decline in mean $\mathrm{S} / \mathrm{C}$ is found which is consistent with the fall in aqueous sulphate observed from dripwater monitoring data from 2002- to 2004 (Spötl et al., 2005) as the catchment recovers from the effects of acid deposition in the late $20^{\text {th }}$ century.

\section{Event laminae}

Smith et al. (2009) reported ion probe analyses of positive secondary ions from the Obir stalagmites which demonstrated a strong annual covariation of $\mathrm{H}, \mathrm{P}, \mathrm{Na}$ and $\mathrm{Mg}$ with enrichments centred around the event laminae, where Sr decreases. The Sr pattern was found to be most reliable for using trace element layers to determine the rate of stalagmite growth. For Obi84, a principal component analysis found that this explained $55 \%$ of the variation in elemental chemistry, with a further $23 \%$ being explained by an independent mode of $\mathrm{Sr}$ and $\mathrm{Ba}$ variability (these results were obtained on data from which long-term trends had been removed). This pattern of variability is illustrated for the years 19581966 in Figure 8a. A discrepancy with Grotta di Ernesto stalagmites is that Mg increases in event laminae, whereas it does not usually do so in Ernesto stalagmites. It also varies annually in the Obir stalagmites typically by a factor of 2 , much more than observed from the equivalent dripwater chemistry. These observations either imply that there are growth factor influences on $\mathrm{Mg}$ incorporation (Fairchild \& Treble 2009), or that there was an independent mode of enrichment of Mg.

Further ion probe analyses of negative secondary ions were later undertaken in order to study the pattern of halogen elements. The iodine analyses are the first such data from a speleothem. Figure $8 \mathrm{~b}$ shows a strong pattern of enrichment in $\mathrm{F}, \mathrm{Br}$ and I coinciding with $\mathrm{P}$. Cl, some of which may be a surface contamination, displays little variability. These elements, like the positive ions, show more than one peak per year in the period 1962-1965; such noise in some years was noted in Smith et al. (2009), but the annual pattern dominates overall.

A more specific imaging of elemental variations in event laminae proved to be possible using synchrotron radiation. The soft X-ray studies showed a particularly strong response from the M-shell of $\mathrm{Pb}$. Lead was seen to be periodically strongly enriched with a spatial pattern matching the distribution of event laminae (Fig. 9).

Mapping of elemental distribution across event laminae was carried out within a zone in the sample that was also subsequently used for the EBSD analysis of Fig. 2. Figure 10a illustrates a map of several annual layers with $\mathrm{Pb}$ enrichments, and the boxed area was analyzed at ultra-high resolution (Fig. 10b). The results obtained require some knowledge of the physics of X-ray generation for their interpretation. The spectrum (Fig. 10c) reflects the excitation of various elements by radiation with energy of $2.9 \mathrm{keV}$. The sensitivity of excitation decreases rapidly at lower energies and is not high enough to excite $\mathrm{Ca}$, so the consistent total ion flux is used to justify an assumption that the element records are concentrations. Normally, only K-shell excitation is expected, but if the concentration of an element is high, L- and even $\mathrm{M}$-shell excitation can occur. Since the $\mathrm{Pb}$ is abundant in the sample and the M-shell signal lies fairly close to the excitation energy, this technique proved especially sensitive for $\mathrm{Pb}$. Zn L-shell excitation also proved much stronger than $\mathrm{Na} \mathrm{K}$-shell excitation (Fig. 10c), but was much less responsive than the $\mathrm{Pb}$ peak. $\mathrm{P}$ and $\mathrm{Mg} \mathrm{K \alpha}$ radiation could also be detected. A key point is that the use of soft X-rays causes excitation very close to the sample surface and so generates a sharply defined truly 2-dimensional map, so the sample offers exceptional clarity of the distribution of $\mathrm{Pb}$.

Figure $10 \mathrm{~b}$ illustrates two features. Running horizontally across the maps is the position of the infiltration lamina. Within a broad zone in the centre of the map enrichment in $\mathrm{Pb}, \mathrm{Zn}$ and $\mathrm{P}$ can be seen. It is hard to discern a similar enrichment in $\mathrm{Mg}$, but this peak is weaker and $\mathrm{Mg}$ in any case does not normally show the annual pattern quite as distinctly as P (Fig. 8a). This broad zone is 15-20 $\mu \mathrm{m}$ high compared with the 80-150 $\mu \mathrm{m}$ thickness of the entire annual layers in Fig. 10a and therefore only forms during a subordinate part of the year (perhaps 1 to 3 months). Within the enriched zone, two continuous peaks in $\mathrm{Pb}$ (and less distinctly in $\mathrm{Zn}$ and $\mathrm{P}$ ) are visible 1-2 pixels (i.e. 1-2 $\mu \mathrm{m}$ ) across. 
517 Based on the annual growth rate, the narrow metal peaks must represent individual events of at most a 518 few days duration when $\mathrm{Pb}$ and other elements were flushed onto the stalagmite. Also visible in Fig. $51910 \mathrm{~b}$ are structural features running NE-SW across the maps. These have the same dimensions as the 520 crystallites of Fig. 2c and Fig. $3 \mathrm{~b}$ and so demonstrate a different chemical composition associated with the flat crystal faces of Fig. $3 \mathrm{~b}$ compared with the rough surfaces that surround them (corresponding also to the zigs and the zags of laminae in Fig. 3a and 4a).

Obi84 was also studied using hard X-ray synchrotron excitation, with energy of $23 \mathrm{keV}$, on a portion of the sample just below the very top surface and representing up to eight years of growth (Fig. 11). This yields a spectrum with a much higher continuum background (Fig. 11a) and in which there are many peak overlaps. The strongest peaks are for $\mathrm{Zn}(\mathrm{L}), \mathrm{Ca}(\mathrm{K}), \mathrm{Pb}(\mathrm{L})$ and $\mathrm{Sr}(\mathrm{L})$. Y may be just quantifiable from its $\mathrm{K} \beta$ peak, but its $\mathrm{K} \alpha$ peak overlaps with a $\mathrm{Pb}$ peak. The broad annual patterns of enrichment in $\mathrm{Zn}$ and $\mathrm{Pb}$ are matched by small reductions in $\mathrm{Sr}$, whilst $\mathrm{Ca}$ variation is limited which confirms that the other elements can be interpreted as concentrations. Under these high-energy conditions, excitation takes place at much greater depths and over a larger range of depths than under the conditions of imaging of Fig. 10, hence providing images integrated over a larger thickness. Thus it would normally be expected that a less sharp image would be obtained unless chemical zones were precisely perpendicular to the excitation path which is $45^{\circ}$ from the surface. This explains the details in the $\mathrm{Pb}$ and $\mathrm{Zn}$ maps which reveal fine bands of enrichment within individual crystallites in slightly different positions. Hence one time-band forms a series of sweeping curves in the image and it is difficult to reconstruct just how many are present in one annual layer.

\section{Discussion}

\section{Chemical control of crystal fabrics}

The Obir stalagmites, and specifically Obi84 which has been studied in most detail, display a series of striking fabric characteristics, some of which have not been previously recorded. However, their preferred optical orientation is a common characteristic of speleothems. In freely growing columnar crystals this preferred orientation arises through geometrical selection, whereby crystals oriented perpendicular to the growth surface grow fastest and become predominant "taking over" the individuals that are not favourably oriented (Dickson, 1993, Onac, 1997). The resulting aggregates can be optically length-fast or length-slow dependent on crystal morphology (Dickson 1993). However speleothem growth is confined within a mm-scale solution film (Dreybrodt 1988) which limits competition to periods whilst crystals are still small, at the beginning of growth, or following a hiatus when heterogeneous renucleation is often observed. Hence, the similar optical orientation of adjacent composite crystals at the top of Fig. $2 \mathrm{~b}$ implies that competition has occurred.

Speleothems often are formed of composite (rarely of single) crystals with uniform extinction (Frisia et al. 2000). Commonly, the columnar crystals will be characterized by an overall orientation of the $\mathrm{z}$ axis (the $<0001>$ direction) roughly perpendicular to the speleothem surface. If the system is not disturbed by the presence of growth inhibitors, such as organic compounds or trace metals, or by changes in flow at the top of the speleothem, the crystallites covering the top of the stalagmites will be characterized by rhombohedral faces with very few defects. In the case of columnar crystals (sensu Frisia et al. 2000), the crystallites would be expected to be strictly parallel in lattice orientation, whereas in microcrystalline calcite (sensu Frisia et al. 2000), some mismatches in orientation of crystallites are found. Microcrystalline calcite is typically associated with perturbations of the system with selective adsorption of species from solution on particular surfaces. The result is a change in the morphology of calcite crystals, with the formation of macrosteps which indicate the presence of crystal defects (Frisia et al., 2000; Jimenez-Lopez et al., 2003; Fernandez-Diaz et al., 2006). In Obi84, XRD data demonstrates that there is a distortion of the lattice induced by substitution for Ca of the smaller ions $\mathrm{Mg}$ and $\mathrm{Zn}$ and the presence of non-divalent ions such as phosphate and halides implies significant substitution in defect sites. These impurities may cause the development of sweeping extinction patterns, even in the quasi-columnar composite crystals near the growth axis of the stalagmite. In the off-axis area studied by EBSD, adjacent crystallites are seen to differ in lattice orientation. 
The SEM image of the top of Obi84 shows the predominance of unstable surfaces, that is, those characterized by macrosteps, with only subordinate flat, defect-free faces. Also, we did not observe calcite rhombohedra tips typically found at the surface of speleothems. Cave precipitation experiments carried out in other caves, and in particular at Grotta di Ernesto, highlighted the development of stepped crystals with forms deviating from the equilibrium form (i.e. $\{10-14\}$ rhombohedron) when supersaturation or presence of impurities perturbed the system (Frisia et al. 2000). In Obi84 each crystallite displays a single, poorly developed flat face possibly pertaining to $\{10-11\}$. The appearance of macrosteps and the deviation from the equilibrium rhombohedra morphology have been documented by Braybrook et al. (2002) who grew calcite crystals doped with cobalt. By increasing the concentration of this trace metal in the growth medium, the morphology of calcite crystals became progressively anisotropic, probably because of the preferential localization of the dopant at the crystal surface (Reeder 1996) and the preferential development of a face in the $\{10-11\}$ form was found. $\mathrm{Zn}$ has a very similar ion size to Co, and similarly adsorbs strongly to calcite surfaces, forming distinct phases at higher concentrations (Zachara et al. 1991). Zn prefers the opposite surface site to Co (Reeder 1996) and yet despite this, Reeder et al. (1999) showed from X-ray absorption fine-structure studies that $\mathrm{Co}, \mathrm{Pb}, \mathrm{Zn}$ and $\mathrm{Ba}$ in calcites all adopted octahedrally-coordinated Ca-substituted lattice positions with varying degrees of local distortion around the ions. Many trace species are present in Obi84, of which $\mathrm{Zn}$ and $\mathrm{Mg}$ are the most abundant, but the peculiar morphology is not typical of Mg-calcite. Given that the ionic radii of zinc and cobalt are nearly identical a homology with the morphologies identified by Braybrook et al. (2002) seems plausible. The presence of trace metal ions with diverse ionic radii with respect to $\mathrm{Ca}$ may exolain also the observed radiaxial fibrous fabric in some aggregates in Obi 84. Finally, Fig. 10b illustrates differences in composition between alternating zones across crystallites; arguably these could be sector zones, reflecting differential trace metal incorporation in different crystallographic forms (e.g. Reeder and Grams 1987).

It is of interest that despite the strong disequilibrium effects noted above, there is a consistency of mean $\mathrm{Mg}$ data with published literature (Huang et al. 2001) implying that deposition on multi-annual timescales was not strongly out of chemical equilibrium, consistent also with the $\delta^{18} \mathrm{O}$ data. Also $\delta^{13} \mathrm{C}$ data in the speleothem can be regarded as equilibrium values, assuming some further degassing occurs in the field beyond that typical of the dripwaters sampled.

\section{Phenomena responsible for trace element patterns in event laminae}

The coincidence of narrow optically visible laminae with trace element anomalies is striking in the Obir stalagmites. In Smith et al. (2009) we had interpreted these event laminae as forming in the same way as the infiltration laminae from Grotta di Ernesto (Borsato et al. 2007). Our understanding of the Ernesto laminae has progressed through the work of Huang et al. (2001), Fairchild et al. (2001) and Treble et al. (2003) who established a link between P enrichments in stalagmites and patterns of seasonal infiltration. Borsato et al. (2007) went much further in demonstrating a very specific hierarchy of association of trace element enrichments with infiltration laminae which they related to the relative importance of colloidal transport. The most specifically associated element with fluorescent laminae was $\mathrm{Y}$ (a proxy also for behaviour of the heavy rare earths), followed by $\mathrm{Cu}, \mathrm{Pb}$ and $\mathrm{Zn}$, whereas $\mathrm{P}$ and $\mathrm{Br}$ were found to display a rather broader enrichment centred around the infiltration lamina. Sr was depressed, which was interpreted as due to being out-competed for lattice defect sites. Ion microprobe analysis confirmed the role of $\mathrm{Y}$ and also showed that F, $\mathrm{H}$ and $\mathrm{Na}$ were focused around these laminae, although the latter two might reflect the presence of fluid inclusions (Borsato et al. 2007). In the infiltration lamina hypothesis, multiple pulses of trace elements associated with infiltration laminae (Figs. 10 and 11) could be consistent with early work on fluorescence in which multiple laminae were recognized (Shopov et al. 1994) and with monitoring work in modern caves, such as the Shihua Cave near Beijing where a series of pulses of organic carbon are found during a wet season (Tan et al. 2006, Ban et al. 2008). However, a review of all the evidence concerning the Obir laminae indicates that we need to consider two alternative origins: as infiltration laminae, or as aerosol laminae.

The first line of evidence concerns the patterns of chemical change associated with the laminae. Of the colloidally-associated species identified from Ernesto, interferences with more abundant species 
prevented microanalysis of Y in Obi84, but all the other species are found enriched together in event laminae together with iodine, which has been analyzed for the first time. Our unpublished UVfluorescence and Fourier-Transform Infra-Red analyses indicated that the infiltration laminae at Ernesto host organic compounds (previously observed by fluorescence) in addition to trace metals, and literature documents that most trace metals detected could be complexed, especially by humic substances. This fits readily with our identification of iodine enrichments since there is also a large body of evidence, summarized by Steinberg et al. (2008), that a large fraction of soluble iodine is associated with colloidal humic substances in terrestrial environments. It is significant also that $\mathrm{Cl}$, which shows minimal complexing effects, shows no variation in the stalagmite. Hence, this pattern of element enrichments clearly supports a similar mechanism of formation of trace element laminae at both cave sites. However, it should be pointed out that fluorescence is not readily detectable from the Obir samples. Although this is consistent with the much deeper ( $70 \mathrm{~m}$ versus $10-15 \mathrm{~m}$ ) position of Säulenhalle relative to the ground surface compared with Ernesto, it also makes it surprising that the trace element enrichments are so clearly developed at these depths.

Secondly, we need to consider the delivery of the elements to the speleothem. A mass balance can be calculated for Obi84 given the mean discharge of dripwater at this site (which varies less than the other drips studied, Table 1, the mean composition of dripwaters (Tables 1 and 4), and the mean composition of the top $10 \mathrm{~mm}$ of the stalagmite (Table 2). The annual discharge is 287 litres and the annual volume of calcite precipitated on the top surface of the stalagmite is approximately $0.23 \mathrm{~g}$ (given a thickness of $0.12 \mathrm{~mm}$ and diameter of the top surface of $30 \mathrm{~mm}$ ). The results, in terms of \% removal of the species from the solution, are shown in Table 5 along with the distribution coefficients previously discussed. It can be seen that only a small fraction $(0.63 \%)$ of $\mathrm{Ca}$ is removed from the dripwater and much smaller percentages of $\mathrm{Mg}, \mathrm{Cu}$ and $\mathrm{Y}$. However the calculated figures for $\mathrm{Zn}$ $(5.7 \%)$ and $\mathrm{Pb}(14 \%)$ are high, but still well below 100\%. Hence, on an annual basis, dripwaters could supply sufficient trace elements. However, as has been shown, the event laminae display concentrations 3-10 times higher than outside these zones, but there is no indication of a seasonal variability in concentration, even though three samples were collected in November when infiltration might be expect to be at a maximum. It appears that much higher rates of delivery of ions is required in the autumn season and yet the dripwater data do not clearly indicate higher rates of discharge at this time. Using the plumbing model concepts in Tooth and Fairchild (2003) and Fairchild et al. (2006b), it is conceivable that a small proportion of water from a fracture-fed source could have had more influence in the autumn if it entered a reservoir with an overflow such that the outflow to the drip had an approximately constant pressure head, but in the absence of evidence for enhanced trace element concentrations in autumn dripwater, this could be regarded as special pleading.

Given the uncertainty as to whether dripwater could supply sufficient elements for the event laminae, we now consider an alternative explanation is that the trace element enrichments represent deposition from aerosol in the cave system. This hypothesis only emerged after our analyses and specifically after the period of more intense cave monitoring at this logistically difficult site. As a result, we currently lack specific observations that could be used to support this hypothesis, so we will argue in more general terms. One point that emerged from the ${ }^{14} \mathrm{C}$ study in Smith et al. (2009) was the result that the ${ }^{14} \mathrm{C}$ concentration of the speleothems increased in parallel with that of the external atmosphere during the era of atmospheric bomb testing: hence there must be isotopic exchange of carbon between air and solution, despite the net degassing of the latter. This result was unexpected, but draws attention to the air as a potential source of chemical species for speleothem deposition.

Aerosols (liquid droplets and fine particles) are generated within the cave system or brought from the outer atmosphere within the cave by air currents (Cigna and Hill, 1997). Deposition from aerosols contributes to the accretion of speleothem deposits at certain sites. However, the main issue in the literature, has been whether speleothems could be entirely explained from aerosol deposition (Cigna and Hill (1997). At Obir, it is accepted that the main crystal growth originates from solution: the only question is whether aerosols might add to the solutes supplied from dripwater during the formation of event laminae in particular. 
In an extensive study on the physics of cave passages, Badino (1995) suggested that aerosols deposit onto speleothems in zones where air currents are feeble to stagnant through the phenomenon of "evaporation", i.e. when the dimensions of the aerosol particles decrease below a critical size (the pressure within the aerosol droplet drops and the surrounding cave air equilibrates with a pressure which is similar to that of the disappearing aerosol droplet). If these aerosol carry trace metals as particulate they may deposit their load onto the growing speleothem surface.

An instructive case study is provided by the work of Jeong et al. (2003) and Chang et al. (2008) on pervasive black carbon deposits on speleothems from touristic caves in Korea. Microscopic and ${ }^{14} \mathrm{C}$ studies were used to identify the sources of carbon as being both from vehicle exhausts and biomass burning (the latter potentially being both external and internal to the cave). Elevated levels of Mn, N, S and $\mathrm{Pb}$ were attributed to airborne anthropogenic sources. The organic carbon was of colloidal dimensions (20-50 $\mathrm{nm}$ ) and so clearly would be much more mobile than pollen grains which are known to be aerially transported only close to the entrance of cave systems (McGarry and Caseldine 2004).

We must stress that although the circulation at Obir is efficient, strong draughts are not felt in the cave interior (flows of up to $0.5 \mathrm{msec}^{-1}$ at constrictions were mentioned earlier) and flows within chambers could even be laminar. Hence we do not anticipate that micron-scale particulates (e.g. rock flour) are transported, but smaller colloidal (organic-hosted) entities should be. A suggestive piece of evidence is the observed and irregular increase in air temperature at the beginning of the winter circulation regime (Fig. 1). This may imply a more vigorous circulation regime at the time, which could be equated with the event laminae that overlap with and are partly followed by the low-S winter growth. For example in autumn 2003, four distinct pulses of higher temperature can be recognized (Fig. 1), which are likely to reflect changes in the intensity of air circulation. Such pulses would be responsible for the distinct micron-scale enrichments in metal content observed in Figs. 10 and 11.

The chemical properties of the elements found enriched in the event laminae are distinctive and are precisely those expected from binding to organic matter, supporting their interpretation as originally bound to soil humic substances. Therefore an overall two-stage hypothesis for the development of the event laminae can be tentatively proposed as:

1. Delivery of elements bound to colloidal humic substances in solutions percolating through fracture-fed components of the karstic aquifer into the cave system and

2. Suspension of part of the colloidal material as aerosol and redistribution within the cave system.

These and other models will be tested in future observations at the study site.

\section{Expressions of seasonality and proxies for climate}

This study has been based on samples that show strongly developed seasonality. The most obvious effect observed during monitoring is the development of a stronger winter circulation, once the external temperature falls below that of the interior, associated with reduced $\mathrm{PCO}_{2}$ in cave air. The most obvious annual phenomenon in the speleothems are the event laminae (of the order of $10^{-1}$ years), many of which are composite of individual events representing only a few days growth. The enrichment in trace elements expected to be associated with organic colloids could be interpreted as reflected a seasonal hydrological flushing as in the model set up for Grotta di Ernesto (Smith et al. 2009). Borsato et al. (2007) found the most convincing relationship between abundance of such elements and surface conditions for the Ernesto cave stalagmite arose when a period of deforestation around World War I led to enhanced metal contents. However, in sample Obi84, although year-to-year variability in element abundances is strong, it is not related to the interannual variability in the intensity of autumnal rainfall (Fig. 9). Neither has cave monitoring has not detected changes in the flux of elements in dripwater, whereas there is evidence for unusually high and fluctuating airflows at the start of the winter season. For this reason, an aerosol origin for event laminae is proposed as an alternative model for testing in future work.

The reduction in $\mathrm{CO}_{2}$ content of cave air in the winter, as observed by monitoring, in itself leaves no physical trace in the speleothem unlike the changes in saturation state in caves in seasonally dry climates where clear and cloudy calcites alternate seasonally (Genty and Quinif 1996, Baker et al. 
2008). However, we have demonstrated from $\delta^{13} \mathrm{C}$ and sulphate evidence that the effects of low $\mathrm{PCO}_{2}$ in winter do have a distinct chemical expression which accords with theory and previous experimental evidence.

Unlike the Ernesto cave, the rate of speleothem growth is not proportional to temperature, but instead has decreased since the mid $19^{\text {th }}$ century. It is plausible that this may relate to a reduction in the severity of winters, leading to less influence of winter ventilation, associated with high supersaturations apply. We do not present here our work on statistical comparison with climatic indices, but suffice to say that any correlations are weak. Obir speleothems, like the physiological variation of the cave system through the year, are remarkable, and should yet yield more specific information that can be interpreted in terms of seasonality under past conditions. We are currently working on the premise that it is the length of the winter season during which strong ventilation applies (currently around 4 months) which is the key factor and have recently obtained more high-resolution S profiles to try to test $\mathrm{S}$ variation as a proxy for the duration of the winter season.

This work was initiated during a Royal Society joint project grant between IJF and CS with assistance from Anna Tooth, and funding continued under the UK Natural Environment Research Council grants NER/T/S/2002/00448 and NE/C511805/1 (IJF principal investigator) and funding from the European Synchrotron Facility (allocations ME1103 and EC104, SF principal investigator). CS acknowledges laboratory assistance by Manuela Wimmer and partial support from FWF grant Y122-GEO. EIMF staff associated with this work are Nicola Cayzer, John Craven and Richard Hinton. We thank staff at the former NERC ICP-MS facility at Kingston University for their assistance and Dr. Louise Male (University of Birmingham) for the X-ray diffraction data. 


\section{References}

Badino, G., 1995. Fisica del clima sotterraneo. Memorie dell'Istituto Italiano di Speleologia 7, Serie II, Bologna, 137 pp. (in Italian)

Baker, A., Genty, D., Dreybrodt, W., Barnes, W. L., Mockler, N. J. \& Grapes, J. 1998. Testing theoretically predicted stalagmite growth rate with recent annually laminated samples: Implications for past stalagmite deposition. Geochimica et Cosmochimica Acta, 62, 393-404.

Baker, A., Smith, C.L., Jex, C., Fairchild, I.J., Genty, D. \& Fuller, L. 2008. Annually laminated speleothems: a review. International Journal of Speleology, 37, 193-206.

Baldini, J.U.L., McDermott, F. \& Fairchild, I.J. 2006 Spatial variability in cave drip water hydrochemistry: Implications for stalagmite paleoclimate records. Chemical Geology, 235, 290-304

Ban, F., Pan, G., Zhu, J., Cai, B. \& Tan, M. 2008. Temporal and spatial variations in the discharge and dissolved organic carbon of drip waters in Beijing Shihua Cave, China. Hydrological Processes, 22, 3749-3758.

Borsato, A., Frisia, S., Fairchild, I.J., Somogiy, A. \& Susini, J. 2007. Trace element distribution patterns in annual stalagmite laminae mapped by micrometer-resolution X-ray fluorescence: incorporation of colloidally-transported species. Geochimica et Cosmochimica Acta, 71, 1494-1512.

Braybrook, A.L., Heywood, B.R., Jackson, R.A. \& Pitt, K. 2002. Parallel computational and experimental studies of teh morphological modification of calcium carbonate by cobalt. Journal of Crystal Growth, 243, 336-344.

Busenberg, E. \& Plummer, L.N. 1985. Kinetic and thermodynamic factors controlling the distribution of $\mathrm{SO}_{4}{ }^{2-}$ and $\mathrm{Na}^{+}$in calcites and selected aragonites. Geochimica et Cosmochimica Acta, 49, 713-725.

Chada, V.G.R., Hausner, D.B., Strongin, D.R., Rouff, A.A. \& Reeder, R.J. 2005. Divalent Cd and Pb uptake on calcite \{10bar14\} cleavage faces: An XPS and AFM study. Journal of Colloid and Interface Science, 288, 350-360.

Chang, S.J., Jeong, G.Y. \& Kim, S.J. 2008. The origin of balck carbon on speleothems in tourist caves in Suth Korea: Chemical characterization and source discrimination by radiocarbon measurement. Atmospheric Environment, 42, 17901800.

Cigna, A.A. \& Hill, C.A. 1997. Aerosols: are they a mechanism of speleothem growth? In: Hill, C. \& Forti, P. (eds) Cave Minerals of the World, National Speleological Association, Huntsville, Alabama, 255-258.

Curti, E. 1999. Coprecipitation of radionuclides with calcite: estimation of partition coefficients based on a review of laboratory investigations and geochemical data. Applied Geochemistry, 14, 433-445.

Dickson, J.A.D. 1993. Crystal-growth diagrams as an aid to interpreting the fabrics of calcite aggregates. Journal of Sedimentary Petrology, 63, 1-17.

Dreybrodt, W. 1988. Processes in Karst Systems. Springer-Verlag, Berlin.

Fairchild, I.J. \& McMillan, E.A. 2007. Speleothems as indicators of wet and dry periods. International Journal of Speleology, 36, 79-84.

Fairchild, I.J. \& Treble, P.C. 2009. Trace elements in speleothems as recorders of environmental change. Quaternary Science Reviews, $\mathbf{x x}, \mathrm{xxx}-\mathrm{xxx}$.

Fairchild, I. J., Borsato, A., Tooth, A. F., Frisia, S., Hawkesworth, C. J., Huang, Y. M., McDermott, F. \& Spiro, B. 2000. Controls on trace element ( $\mathrm{Sr}-\mathrm{Mg}$ ) compositions of carbonate cave waters: implications for speleothem climatic records. Chemical Geology, 166, 255-269.

Fairchild, I. J., Baker, A., Borsato, A., Frisia, S., Hinton, R. W., McDermott, F. \&Tooth, A. F. 2001. Annual to sub-annual resolution of multiple trace-element trends in speleothems. Journal of the Geological Society, London, 158, 831-841.

Fairchild, I. J., Smith, C. L., Baker, A., Fuller, L., Spötl, C., Mattey, D., McDermott, F. \& E.I.M.F. 2006a. Modification and preservation of environmental signals in speleothems. Earth-Science Reviews, 75, 105-153.

Fairchild, I.J., Tuckwell, G.W., Baker, A. \& Tooth, A.F. 2006b. Modelling of dripwater hydrology and hydrogeochemistry in a weakly karstified aquifer (Bath, UK): implications for climate change studies. Journal of Hydrology, 321, 213-231.

Fairchild, I.J., Frisia, S., Borsato, A. \& Tooth, A.F. 2007. Speleothems. In: Geochemical Sediments and Landscapes (ed. Nash, D.J. and McLaren, S.J.), Blackwell, Oxford, p. 200-245.

Fernández-Diaz, L., Astilleros, J.M. \& Pina, C.M. 2006. The morphology of calcite crystals grown in a porous medium doped with divalent cations. Chemical Geology, 225, 314-321.

Frappier, A., Sahagian, D., Gonzalez, L.A. \& Carpenter,S.J. 2002. El Niño events recorded by stalagmite carbon isotopes. Science, 298, 565.

Frisia, S., Borsato, A., Fairchild, I.J. \& McDermott, F. I.J. 2000. Calcite fabrics, growth mechanisms and environments of formation in speleothems (Italian Alps and SW Ireland). Journal of Sedimentary Research, 70, 1183-1196.

Frisia, S., Borsato, A., Preto, N. \& McDermott, F. 2003. Late Holocene annual growth in three Alpine stalagmites records the influence of solar activity and the North Atlantic Oscillation on winter climate. Earth and Planetary Science Letters, 216, 411-424.

Frisia, S., Borsato, A., Fairchild, I.J. \& Susini, J. 2005. Variations in atmospheric sulphate recorded in stalagmites Variations in atmospheric sulphate recorded in stalagmites by synchrotron micro-XRF and XANES analyses. Earth and Planetary Science Letters, 235, 729-740.

Genty, D. \& Quinif, Y. 1996. Annually laminated sequences in the internal structure of some Belgian stalagmites importance for paleoclimatology. Journal of Sedimentary Research, 66, 275-288. 
Godelitsas, A., Astilleros, J.M., Hallam, K., Harissopoulos, S. \& Putnis, A. 2003. Interaction of calcium carbonates with lead in aqueous solutions. Environmental Science and Technology, 37, 3351-3360.

Huang, Y. \& Fairchild, I.J. 2001. Partitioning of $\mathrm{Sr}^{2+}$ and $\mathrm{Mg}^{2+}$ into calcite under karst-analogue experimental conditions. Geochimica et Cosmochimica Acta, 65, 47-62.

Huang, H. M., Fairchild, I. J., Borsato, A., Frisia, S., Cassidy, N. J., McDermott, F. \& Hawkesworth, C. J. 2001. Seasonal variations in $\mathrm{Sr}, \mathrm{Mg}$ and $\mathrm{P}$ in modern speleothems (Grotta di Ernesto, Italy). Chemical Geology, 175, 429-448.

Jeong, G.Y., Kim, S.J. \& Chang, S.J. 2003. Black carbon pollution of speleothems by fine urban aerosols in tourist caves. American Mineralogist, 88, 1872-1878.

Jimenez-Lopez, C., Rodriguez-Navarro, A., Dominguez-Vera, J.M. \& Garcia-Ruiz, J.M. 2003. Influence of lysozym on the precipitation of calcium carbonate: A kinetic and morphologic study. Geochimica et Cosmochimica Acta,67, 1667-1676.

Johnson, K. R., Hu, C., Belshaw, N.S. \& Henderson, G.M. 2006. Seasonal trace-element and stable isotope variations in a Chinese speleothem: the potential for high resolution paleomonsoon reconstruction. Earth and Planetary Science Letters, 244, 394-407.

Kendall, A.C. \& Broughton, P.L. 1978. Origin of fabric in speleothems of columnar calcite crystals. Journal of Sedimentary Petrology, 48, 550-552.

Kim S.T. \& O’Neil, J.R. 1997. Equilibrium and nonequilibrium oxygen isotope effects in synthetic carbonates. Geochimica et Cosmochimica Acta, 61, 3461-3475.

Larson, A.C. \& Von Dreele, R.B. 2000. General Structure Analysis System (GSAS), Los Alamos National Laboratory Report, LAUR 86-748.

Mackenzie, F.T., Bischoff, W.D., Bishop, F.C., Loijens, M., Schoonmaker, J. \& Wollast, R. 1983. Magnesian calcites: lowtemperature occurrence, solubility and solid-solution behavior. In: Reeder, R.J. (ed) Carbonates: Mineraology and Geochemistry, Reviews in Mineralogy, 11, 97-144.

Mattey, D., Lowry, D., Duffet, J., Fisher, R., Hodge, E. \& Frisia, S. 2008. A 53 year seasonally resolved oxygen and carbon isotope record from a modern Gibraltar speleothem: Reconstructed drip water and relationship to local precipitation. Earth and Planetary Science Letters, 269, 80-95.

McDermott, F. 2004. Palaeo-climate reconstruction from stable isotope variations in speleothems: a review. Quaternary Science Reviews, 23, 901-918.

McDermott F., Schwarcz H.P. \& Rowe, P.J. 2005. 6. Isotopes in speleothems. In: Leng, M.J. (ed) Isotopes in Palaeoenvironmental Research, Springer, Dordrecht, The Netherlands, 185-225.

McGarry, S.F. \& Caseldine, C. 2004. Speleothem palynology: an undervalued tool in Quaternary studies. Quaternary Science Reviews, 23, 2389-2404.

Mühlingaus, C., Scholz, D. \& Mangini, A. 2007. Modelling stalagmite growth and $\delta^{13} \mathrm{C}$ as a function of drip interval and temperature. Geochimica et Cosmochimica Acta, 71, 2780-2790.

Neuser, R.D. \& Richter, D.K. 2007. Non-marine radiaxial fibrous calcites - examples of speleothems proved by electron backscatter diffraction. Sedimentary Geology, 194, 149-154.

Onac, B, P., 1997. Crystallography of Speleothems In: Hill, C. \& Forti, P. (eds) Cave Minerals of the World, National Speleological Association, Huntsville, Alabama, 230-235.

Reeder, R.J. 1983. Crystal chemistry of the rhombohedral carbonates. In: Reeder, R.J. (ed) Carbonates: Mineraology and Geochemistry, Reviews in Mineralogy, 11, 1-47.

Reeder, R.J. 1996. Interaction of divalent cobalt, zinc, cadmium, and barium with the calcite surface during layer growth. Geochimica et Cosmochimica Acta, 60, 1543-1552.

Reeder, R.J. \& Grams, J.C. 1987. Sector zoning in calcite cement crystals: Implications for trace element distributions in carbonates. Geochimica et Cosmochimica Acta, 51, 187-194.

Reeder, R.J., Lamble, G.M. \& Northrup, P.A. 1999. XAFS study of the coordination and local relaxation around Co ${ }^{2+}$, $\mathrm{Zn}^{2+}, \mathrm{Pb}^{2+}$, and $\mathrm{Ba}^{2+}$ trace elements in calcite. American Mineralogist, 84, 1049-1060.

Rimstidt, J.D., Balog, A. \& Webb, J. 1998. Distribution of trace elements between carbonate minerals and aqueous solutions. Geochimica et Cosmochimica Acta, 62, 1851-1863.

Roberts, M. S., Smart, P. \& Baker, A., 1998. Annual trace element variations in a Holocene speleothem. Earth and Planetary Science Letters, 154, 237-246.

Shopov, Y.Y., Ford, D.C. \& Schwarcz, H.P. 1994. Luminescent microbanding in speleothems: High-resolution chronology and palaeoclimate. Geology 22, 407-410.

Smith, C.L., Baker, A., Fairchild, I.J., Frisia, S. \& Borsato, A. 2006. Reconstructing hemispheric-scale climates from multiple stalagmite records. International Journal of Climatology, 26, 1417-1424.

Smith, C.L., Fairchild, I.J., Spötl, C., Frisia, S., Borsato, A., Moreton, S.G. \& Wynn, P.M. 2009. Chronology-building using objective identification of annual signals in trace element profiles of stalagmites. Quaternary Geochronology, 4 , $11-21$.

Solé, V.A. Papillon, E., Cotte, M., Walter, P. \& Susini, J., 2007. PyMCA: A multiplatform code for the analysis of energydispersive X-ray fluorescence spectra. Spectrochimica Acta B, 62, 63-68.

Spötl, C. \& Mattey, D.P., 2006. Stable isotope microsampling of speleothems: a comparison of manual drill, micromill and laser ablation techniques. Chemical Geology, 235, 48-58.

Spötl, C. \& Vennemann, T.W., 2003. Continuous-flow isotope ratio mass spectrometric analysis of carbonate minerals. Rapid Communications in Mass Spectrometry, 17, 1004-1006. 
Spötl, C., Fairchild, I. J. \& Tooth, A. F. 2005. Cave air control on dripwater geochemistry, Obir caves (Austria): implications for speleothem deposition in dynamically ventilated caves. Geochimica et Cosmochimica Acta, 69, 24512468.

Steinberg, S.M., Kimble, G.M., Schmett, G.T., Emerson, D.W., Turner, M.F. \& Rudin, M. 2008. Abiotic reaction of iodate with sphagnum peat and other natural organic matter. Journal of Radioanalytical and Nuclear Chemistry, 277, 185-191.

Tan, M., Baker, A., Genty, D., Smith, C., Esper, J. \& Cai, B., 2006. Applications of stalagmite laminae to paleoclimate reconstructions: comparison with dendrochronology/climatology. Quaternary Science Reviews, 25, 2103-2117.

Tooth, A.F. \& Fairchild, I.J. 2003 Soil and karst aquifer hydrological controls on the geochemical evolution of speleothemforming drip waters, Crag Cave, southwest Ireland. Journal of Hydrology, 273, 51-68.

Treble, P., Shelley, J.M.G. \& Chappell, J. 2003. Comparison of high resolution sub-annual records of trace elements in a modern (1911-1992) speleothem with instrumental cliate data from southwest Australia. Earth and Planetary Science Letters, 216, 141-153.

Wynn, P.M., Fairchild, I.J., Spötl, C. \& EIMF 2009. High resolution sulphur isotope analysis of speleothem carbonate by ion microprobe. Chemical Geology (submitted)

Zachara, J.M., Cowan, C.E. \& Resch, C.T. 1991. Sorption of divalent metals on calcite. Geochimica et Cosmochimica Acta, 55, 1549-1562.

\section{Figure captions}

Fig. 1. Characteristics of Saulenhalle drips, mostly using continuously logged data. Features of all four drips, including the three feeding the studied stalagmites is a lack of clear seasonality and large inter-annual variations in mean drip rate. Water temperature is given for dripSH3 (Obi55) as an example for comparison with air temperature. The two follow a similar pattern of a rise followed by a fall during the winter season; this is attributed to the forcing effects of winter air ventilation.

Fig. 2. Petrology of stalagmite sample Obi84. a. image of ion microprobe section with calendar ages of annual laminae superimposed. In the central part of the speleothem the laminae are approximately tabular and horizontal, but curve and merge on the lateral flanks. b. Photomicrograph under crossed polars of thin section made from synchrotron sample (viewed to a similar sample depth as in photograph a.) illustrating quasi-columnar crystal morphology approximately normal to growth surface. "S" indicates example of crystal with undulose (specifically, radiaxial) extinction (see text). Small red rectangle indicates area of electron backscatter diffraction (EBSD) map. c. EBSD map of a grid of 931 by 701 points at $1 \mu \mathrm{m}$ resolution. The map has been false-coloured to highlight the relative crystallographic orientations of the calcite across the map. The colour range blue to red indicates a $0^{\circ}$ $15^{\circ}$ deviation in orientation with respect to the crystallographic orientation of the calcite at the reference point indicated by the red cross near the centre. The large crystals to the right of the map are grey and have no colour as the orientation of these crystals differ by more than $15^{\circ}$ from that of the reference point (see also Figure 1d). Scattered grey pixels in the upper and left areas of the map were the results of systematic mis-indexing of the calcite diffraction patterns while others (mostly in the central areas of the map) represent locations where the quality of the diffraction pattern was too poor to give a solution for the crystallographic orientation of the calcite and were assigned a zero solution. The map shows that the large crystals are divided into crystallites around $10 \mu \mathrm{m}$ wide. d. Upper-hemisphere stereographic projections of the poles to potential indicated crystal forms for the crystals illustrated in the EBSD map in Figure 1c. The XY plane of the projections is that of the surface of the sample section. The colours shown correspond to those in Figure 1c. The reference point (red cross) shown in Figure 1c was chosen as having a crystallographic orientation close to the centre of the brightly coloured clusters. The grey clusters indicate the orientation of the large (grey) crystals to the right of Figure 1c. The $\{0001\}$ diagram also corresponds to the zone axis and orientation of the $\mathrm{z}$ crystallographic axis which can be seen to be sub-vertical in the diagram, corresponding to subperpendicular to the elongation and growth directions of crystals at the top of the stalagmite, i.e. the crystals are optically length-slow. The $\{10-11\}$ diagram displays a pole to one face approximately in the equatorial plane: this is thought to be equivalent to the flat face seen on crystallite tops in Fig. $3 \mathrm{~b}$.

Fig. 3. Petrology of sample Obi84. a. ion probe thin section, transmitted light illustrating a series of annual event laminae with the last one being close to the top of the sample prior to collection in 
December 2002. Zig-zag crystallite shapes are visible, and are of much higher relief in the 1998 layer, apparently corresponding to a pit on the crystal surface which subsequently evolves into a (black) air inclusion. A within-year hiatus prior to the 2000 infiltration lamina is marked by a re-nucleation horizon (hi). b. SEM of top surface of sample illustrating crystallites which display a mixture of flat smooth surfaces and rough surfaces representing stacked edges.

Fig 4. Stalagmite petrology. a. Sample Obi 84, transmitted light, illustrating two annual infiltration laminae. The lower one illustrates three (arrowed) sub-laminae plus internal reflections, whereas the upper one is a single lamina. The fibrous sub-vertical structure of crystallites is seen to correspond to the zig-zag lamina structure. b. Sample Obi84. Arrow illustrates hiatus between infiltration laminae for the years 1889 and 1890. To the left of the arrow the hiatus disappears. To the right (the stalagmite flank) various laminae converge to give more prominent hiatus (i.e. renucleation) surface. c. and d. Sample Obi12. c. Prominent hiatus surface with box $(0.9 \mathrm{~mm}$ long $)$ showing location of photo d. d. enlargement of hiatus, illustrating local area where growth continued throughout (arrows indicate individual annual infiltration laminae). The hiatus itself, although very prominent in photo c, is only of three or four years duration.

Fig. 5. Depth trends in stalagmite Obi84 (a to c) and Obi12 (d). a. stable isotope data derived by micromilling at $0.1 \mathrm{~mm}$ intervals; thick lines are 5-point moving averages. b. Variations in lamina thickness; calendar years are shown at 20-year intervals. c and d. Trends in composition with depth from ICP analyses of samples drilled at approximately $1.5 \mathrm{~mm}$ intervals. Data for 10 elements is summarized in Table 1 . S increases during the $20^{\text {th }}$ century whereas the base metals tend to decrease, especially in Obi84.

Fig. 6. Chemical trends in sample Obi84 across an interval of wide laminae corresponding to the years 1958 to 1966 (year marker indicates position of visible infiltration lamina for that year). Compare with Fig 8. a. ion microprobe traverse of negative secondary ions ( $15 \mu \mathrm{m}$ step interval) illustrating the offset of S variability from P. Horizontal bars are low S intervals which tend to overlap with or follow $\mathrm{P}$ peaks. b. Ion microprobe traverse of $\delta^{13} \mathrm{C}$; analytical spots are around $25 \mu \mathrm{m}$ in diameter and spaced at $50 \mu \mathrm{m}$ intervals. Inset photograph illustrates that the points are arranged in interwoven forward-andback arrays which can be identified on dataplot by numbered points. Significant within-year variation in $\delta^{13} \mathrm{C}$ is demonstrated.

Fig. 7. Trends in S and $\mathrm{P}$ in the last few years of growth of sample Obi84. The horizontal scale is distance rather than time since infiltration laminae were not clearly visible in this section, but the $\mathrm{P}$ peaks match the lamina widths in a laterally adjacent profile (but note poor P peak in 1996 and double peak in 2000). S displays low intervals partly overlapping and partly following $\mathrm{P}$ peaks, and also displays a distinct downward inter-annual trend; likewise dripwater sulphate declined by $25 \%$ between 1999 and 2003 in Säulenhalle (Spötl et al. 2005).

Fig. 8. Chemical trends in sample Obi84 for the years 1958 to 1966 (compare with Fig. 6). a. ion microprobe analyses of positive secondary ions (5-point moving average of $5 \mu \mathrm{m}$ steps); note $\mathrm{Sr}$ is on right-hand axis and its scale is linear and reversed. $\mathrm{H}, \mathrm{Mg}, \mathrm{Na}$ and $\mathrm{P}$ tend to peak at visible laminae, inverse to Sr. b. ion microprobe analysis of negative secondary ions ( $5 \mu \mathrm{m}$ steps). P, F, Br and I enrichments coincide with visible laminae, but $\mathrm{Cl}$ does not display distinctive variation.

Fig. 9. Line scan of $\mathrm{Pb}$ (three-point moving average of analyses at $5 \mu \mathrm{m}$ intervals in sample Obi84) using X-ray fluorescence induced by relatively low-energy synchrotron radiation. The concentrations have been normalized to ppm using the mean composition from ICP-MS analysis in the same interval. The depth beneath the top surface of visible annual laminae in a similar, but different slice of the sample is shown as is the magnitude of autumn (September to December) rainfall since the year 1922. 
The highest $\mathrm{Pb}$ peak is closest to 1946 in the chronology of the other slice, but there is a registration uncertainty of \pm 3 years because of the curvature of the laminae.

Fig. 10. Obir84, level within the area of the EBSD map of Fig. 2. X-ray elemental mapping at ultrahigh resolution, sample Obi 84 , induced by relatively low-energy synchrotron radiation. a. a lowresolution map (400 by $100 \mu \mathrm{m}$ ), showing the development of four annual laminae rich in $\mathrm{Pb}$. b. highresolution maps, 30 by $30 \mu \mathrm{m}$ with $1 \mu \mathrm{m}$ pixels of $\mathrm{Pb}, \mathrm{Zn}, \mathrm{P}$ and $\mathrm{Mg}$. The $\mathrm{Pb}$ map displays a $15 \mu \mathrm{m}-$ wide zone of enrichment with two 1-2 $\mu \mathrm{m}$ high- $\mathrm{Pb}$ zones within it. The enrichment zone is also displayed, but less prominently in the $\mathrm{Zn}$ and $\mathrm{P}$ maps. All maps show an oblique structure running from upper right to lower left, seen to correspond to crystallite development by the zig-zag pattern of the $\mathrm{Pb}$ zones. The grey shade linear scale-bar below the image has the following upper and lower limits in counts: $\mathrm{Pb}(0-154), \mathrm{Zn}(0-12), \mathrm{P}(0-31)$ and $\mathrm{Mg}(0-22)$. c. X-ray emission energy spectrum showing the location of peaks used to produce the maps. Elements in small type are too insignificant to quantify. The excitation energy was $2.9 \mathrm{keV}$ and the peak at around this energy is due to scattering.

Fig. 11. X-ray fluorescence mapping using high-energy synchrotron radiation very close to the top of the Obi 84 sample. a. Energy spectrum resulting from excitation with $23 \mathrm{keV}$ radiation. Only $\mathrm{Zn}, \mathrm{Pb}$, $\mathrm{Ca}$ and $\mathrm{Sr}$ can be reliably quantified using a deconvolution procedure. $\mathbf{b}$. scale bars in maps in counts (logarithmic for $\mathrm{Zn}$ and $\mathrm{Pb}$ and linear for $\mathrm{Ca}$ and $\mathrm{Sr}$ ). c. Elemental maps of an area $1.1 \mathrm{~mm}$ by $0.04 \mathrm{~mm}$ at $2 \mu \mathrm{m}$ resolution (top of section at left side). Probably eight annual layers are shown by $\mathrm{Zn}$ and $\mathrm{Pb}$ with a complex pattern of enriched micro-laminae because of excitation of crystallites at different depths below the surface: hence this is a pseudo-3D image. Levels of $\mathrm{Zn}$ and $\mathrm{Pb}$ are more uniformly high in two annual cycles on the far right. 
1001

1002

1003

1004

1005

1006

\begin{tabular}{|c|c|c|c|c|c|c|c|c|c|c|c|c|c|c|c|c|c|c|c|c|c|c|c|}
\hline $\begin{array}{l}\text { Drip } \\
\text { site }\end{array}$ & $\begin{array}{l}\text { Collection } \\
\text { date of } \\
\text { stalagmite }\end{array}$ & $\begin{array}{l}\text { Start date of } \\
\text { observations }\end{array}$ & & $\begin{array}{l}\text { Discharge, } \\
\mu l / s e c\end{array}$ & $\begin{array}{c}\text { mınımum } \\
\text { driprate, } \\
\mu l / s e c\end{array}$ & $\begin{array}{c}\mathrm{EC} \\
\mu \mathrm{s} / \mathrm{cm}\end{array}$ & $\mathrm{pH}$ & $\mathrm{HCO} 3$ & $3 \mathrm{SO} 4$ & $\mathrm{NO} 3$ & $\mathrm{Cl}$ & $\mathrm{Na}$ & $\mathrm{K}$ & $\mathrm{Mg} / \mathrm{Ca}$ & $\mathrm{Ca}$ & $\mathrm{Mg}$ & $\mathrm{Sr}$ & $\mathrm{SiO} 2$ & $\begin{array}{l}\text { Calcite } \\
\text { saturation } \\
\text { index }\end{array}$ & $\mathrm{pCO}_{2}$ & $\delta^{18} \mathrm{O}$ & $\delta \mathrm{D}$ & $\delta^{13} \mathrm{C}$ \\
\hline$\overline{\mathrm{SH} 1}$ & August & September & mean & 2.06 & 0.11 & 292 & 8.19 & 186 & 5.29 & 4.01 & 0.49 & 0.32 & 0.23 & 0.15 & 51.51 & 7.74 & 0.03 & 1.52 & 0.44 & -3.05 & -10.25 & -69.37 & $\overline{-9.91}$ \\
\hline & 1998 & 1998 & stdev & 1.82 & & 11 & 0.15 & 10 & 0.44 & 1.25 & 0.12 & 0.03 & 0.03 & 0.02 & 3.47 & 0.62 & 0.01 & 0.25 & 0.15 & 0.15 & 0.15 & 1.09 & 1.15 \\
\hline
\end{tabular}

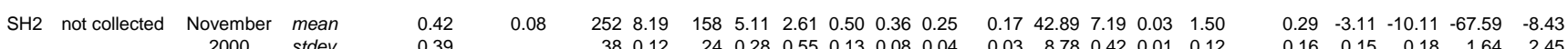

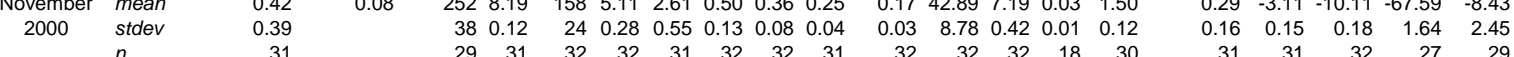
$\begin{array}{llllllllllllllllllllllllllllllllll} & \text { SH3 } & \text { May } & \text { May } & \text { mean } & 4.42 & 2.20 & 296 & 8.23 & 191 & 4.76 & 2.38 & 0.45 & 0.32 & 0.23 & 0.13 & 52.97 & 7.07 & 0.04 & 1.53 & 0.51 & -3.07 & -10.23 & -68.82 & -10.27\end{array}$

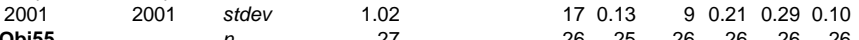
$\begin{array}{lllllllllllllllllllll}\text { December } & \text { February mean } & 9.08 & 2.70 & 299 & 8.24 & 190 & 4.44 & 2.64 & 0.40 & 0.33 & 0.23 & 0.14 & 51.17 & 7.03 & 0.03 & 1.64\end{array}$

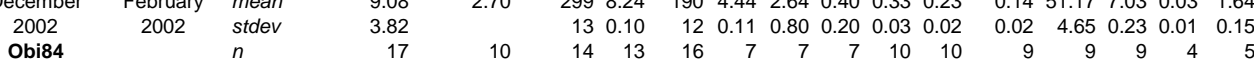

Table 1. Summary of drip hydrochemistry including samples collected to the end of 2003.

\begin{tabular}{cllllllllllll}
$\begin{array}{c}\text { mm } \\
\text { below } \\
\text { top }\end{array}$ & $M g$ & $P$ & $S$ & $M n$ & $\mathrm{Cu}$ & $\mathrm{Zn}$ & $\mathrm{Sr}$ & $\mathrm{Y}$ & $\mathrm{Ba}$ & $\mathrm{Pb}$ & $\begin{array}{c}\text { number } \\
\text { of } \\
\text { analyses }\end{array}$ \\
\hline
\end{tabular}

$\begin{array}{crrrrrrrrrrr}\text { Obi 84 } & & & & & & & & & & \\ 0-10 & 903 & 66 & 42.4 & 0.99 & 2.2 & 3410 & 32.4 & 0.020 & 174 & 500 & 8 \\ 11-20 & 976 & 52 & 6.7 & 1.01 & 2.7 & 4590 & 35.3 & 0.040 & 196 & 770 & 6 \\ >20 & 1040 & 67 & 10.5 & 0.87 & 3.4 & 6420 & 30.9 & 0.039 & 191 & 1360 & 7\end{array}$

1007

1008

1009

1010

1011

1012

1013

1014

1015

1016

1017

1018

\section{Obi 12}

$\begin{array}{crrrrrrrrrrr}0-10 & 1160 & 56 & 30.6 & 1.02 & 4.5 & 4010 & 32.6 & 0.015 & 244 & 370 & 8 \\ 11-20 & 1280 & 67 & 12.8 & 0.67 & 3.8 & 5970 & 29.2 & 0.014 & 234 & 630 & 6 \\ >20 & 1250 & 93 & 17.3 & 1.3 & 5.4 & 5690 & 30.9 & 0.020 & 237 & 510 & 5\end{array}$

Table 2. Bulk compositions of stalagmite samples (ppm in calcite).

\begin{tabular}{|c|c|c|c|c|c|c|}
\hline & $\begin{array}{r}\text { Dripwater } \\
\mathrm{Mg} / \mathrm{Ca}\end{array}$ & $\begin{array}{r}\text { Stalagmite } \\
\mathrm{Mg} / \mathrm{Ca} \text { (top } 0.5 \\
\mathrm{~mm} \text { ) }\end{array}$ & $\mathrm{K}_{\mathrm{Mg}}$ & $\begin{array}{r}\text { Drip water } \\
\text { Sr/Ca }\end{array}$ & $\begin{array}{r}\text { Stalagmite } \\
\text { Sr/Ca (top } \\
\mathbf{m m})\end{array}$ & $\mathrm{K}_{\mathrm{Sr}}$ \\
\hline Obi 12 & $\begin{array}{r}0.15 \\
(0.13-0.21)\end{array}$ & $\begin{array}{r}0.003 \\
(0.0025-0.004)\end{array}$ & 0.020 & $\begin{array}{r}6.9^{*} 10^{-4} \\
\left(5.1-9.0^{*} 10^{-4}\right)\end{array}$ & $\begin{array}{r}9.2^{*} 10^{-5} \\
\left(8.3-9.8^{*} 10^{-4}\right)\end{array}$ & 0.13 \\
\hline Obi 55 & $\begin{array}{r}0.13 \\
(0.12-0.20)\end{array}$ & $\begin{array}{r}0.0024 \\
0.0011-0.0031\end{array}$ & 0.018 & $\begin{array}{r}7.4^{\star} 10^{-4} \\
\left(4.7-8.8^{\star} 10^{-4}\right)\end{array}$ & $\begin{array}{r}8.6^{*} 10^{-5} \\
\left(8.0-9.4^{*} 10^{-4}\right)\end{array}$ & 0.12 \\
\hline Obi 84 & $\begin{array}{r}0.14 \\
(0.13-0.17)\end{array}$ & $\begin{array}{r}0.0021 \\
(0.001--0.0032\end{array}$ & 0.015 & $\begin{array}{r}7.0 * 10^{-4} \\
\left(5.3-9.0^{*} 10^{-4}\right)\end{array}$ & $\begin{array}{r}5.5^{\star} 10^{-5} \\
\left(3.9-7.9^{*} 10^{-4}\right)\end{array}$ & 0.079 \\
\hline
\end{tabular}

Table 3. Mean values (and range in parentheses) of dripwater and stalagmite $\mathrm{Mg}$ and Sr compositions with the calculated value of the distribution coefficient $K$.

\begin{tabular}{|c|c|c|c|c|c|c|c|c|c|c|c|}
\hline & & $\mathrm{Al}$ & $\mathrm{Si}$ & $\mathbf{P}$ & $\mathrm{Fe}$ & $\mathrm{Cu}$ & $\mathrm{Zn}$ & $\mathrm{Sr}$ & $\mathbf{Y}$ & $\mathrm{Ba}$ & $\mathbf{P b}$ \\
\hline \multirow{2}{*}{$\begin{array}{l}\text { SH3 } \\
(n=12)\end{array}$} & mean & 31 & 781 & 48 & 287 & 6.7 & 48 & 38 & 0.020 & 128 & 3.0 \\
\hline & stdev & 31 & 295 & 76 & 36 & 5.5 & 24 & 2 & 0.023 & 4 & 2.3 \\
\hline \multirow{2}{*}{ SH4 $(n=6)$} & mean & 33 & 707 & 38 & 270 & 4.8 & 48 & 34 & 0.021 & 115 & 2.9 \\
\hline & stdev & 29 & 240 & 14 & 38 & 0.8 & 25 & 2 & 0.021 & 8 & 2.1 \\
\hline
\end{tabular}

Table 4. Indicative ICP-MS analyses (in ppb) of drip water trace element compositions for SH3 (Obi55, month-long collection) and SH4 (Obi84, instantaneous collection). 
1019

1020

1021

1022

1023

\begin{tabular}{lcccccc} 
& $\mathbf{C a}$ & $\mathbf{M g}$ & $\mathbf{C u}$ & $\mathbf{Z n}$ & $\mathbf{Y}$ & $\mathbf{P b}$ \\
\cline { 2 - 7 } Distribution coefficient, & - & 0.017 & 0.059 & 9.1 & 0.122 & 22
\end{tabular}

calculated

$\begin{array}{lllllll}\text { \% efficiency of removal } & 0.63 & 0.010 & 0.04 & 5.7 & 0.076 & 14\end{array}$

Table 5. Summary of water-calcite partitioning calculations for the top $10 \mathrm{~mm}$ of Obi84 (SH4) from data in Tables 1 and 4. 